\title{
The incidence of Type 1 (insulin-dependent) diabetes mellitus 15-29 years in Norway 1978-1982
}

\author{
G.Joner ${ }^{1}$ and O.Søvik ${ }^{2}$ \\ ${ }^{1}$ Department of Pediatrics, Aker University Hospital, Oslo \\ ${ }^{2}$ Department of Pediatrics, University of Bergen, Norway
}

\begin{abstract}
Summary. All new cases of Type 1 (insulin-dependent) diabetes mellitus in the 15-29 year age group during the fiveyear period 1978-1982 were registered using a retrospective technique on a nation-wide basis. A total of 784 newly diagnosed cases were detected, from an average population of 926,192 . The degree of ascertainment was almost $90 \%$. The mean yearly incidence for the five-year period was 17.0 per 100,000 . The observed incidence is doubled compared to the incidence found in the city of Oslo during the years 1956-1964 $(8.8$ per 100,000$)$. The male incidence exceeded the female incidence by $12 \%(p<0.05)$. There was a marked geographic variation in incidence, with a higher incidence in the three
\end{abstract}

southern health regions compared to the two northern, $18.3 \mathrm{vs}$ 13.9 per $100,000(p<0.01)$. There was a significant seasonal trend in the incidence data $(p<0.025)$ with the highest number of new cases detected in the months of January and September and the lowest number in July. In conclusion, the study suggests a two-fold increase of incidence of diabetes mellitus in the age group 15-29 years during the last $2-3$ decades and a geographic variation in incidence within the country, pointing to the operation of environmental pathogenic factors.

Key words: Type 1 (insulin-dependent) diabetes mellitus, incidence, geographic pattern, seasons, time factors.
Epidemiological data on Type 1 (insulin-dependent) diabetes mellitus in the age group 0-14 years have been published from various parts of the world during the past few years $[1,2]$. In comparison, relatively little is known about the incidence of Type 1 diabetes after that age, in particular after the age of 19 years. Studies on the incidence of diabetes mellitus in the age groups from 15 to 29 years, or beyond that age, have been conducted in Oslo, Norway [3,4], Rochester Minnesota and Wisconsin, USA [5, 6], Denmark [7], United Kingdom [8], Sweden [9] and Kuwait [10].

Although several studies have suggested a secular increase of the incidence of Type 1 diabetes [11-16] this subject remains controversial. Concerning the geographical variability of the incidence, previous studies in Norway [11] did not fit into the general pattern on a worldwide basis, namely high incidences associated with low mean yearly temperature [1]. We therefore undertook a study in the age group 15-29 years and addressed ourselves mainly to the question of time trend and regional differences of incidence. In the context of Type 1 diabetes, Norway is a high-incidence area [11]. The country has reliable health statistics and a stable and ethnically homogeneous population. For comparative purposes there are reliable studies of diabetes epidemiology, conducted $25-35$ years ago $[3,4]$.

\section{Subjects and methods}

\section{Population and geographical data}

In the study period 1978-1982, Norway had approximately four million inhabitants. About 23\% of the population were in the 15-29 year age group, the yearly mean for the study period being 926,192 persons. Norway has a considerable south-north extension, reaching from the 57 th to the 71 st latitude. The mainland of the country covers about $324,000 \mathrm{~km}^{2}$ and is comprised of 19 counties. There are about 20,000 Lapps and a smaller number of people of Finnish origin, who live mainly in the three northernmost counties. In 1982, there were about 90,000 temporary residents in the country, mostly Europeans.

\section{Collection of data}

A questionnaire was sent to all pediatric and medical hospital departments in Norway. All 19 pediatric departments and 60 out of 63 medical departments responded. Two of the responding medical departments could not produce data for the years 1978-1979 and 1980-1982, respectively. The hospitals reported the following data for all new cases of diabetes mellitus in the age group $0-29$ years during the years 1978-1982: name, sex, date of birth, personal identification code, date of hospital admission, place of residence at the time of admission and whether the patient was on continuous insulin treatment when leaving the hospital. All of the hospital cases re- 
Table 1. Number of cases ascertained from hospital records (source A) and insurance registry (source B)

\begin{tabular}{llll}
\hline & \multicolumn{2}{l}{ Hospital records } & \\
\cline { 2 - 3 } & + & - & Total \\
\hline Insurance registry & & & \\
+ & $378^{\mathrm{a}}$ & $195^{\mathrm{b}}$ & 573 \\
- & $211^{\mathrm{c}}$ & $\mathrm{x}$ & \\
Total & 589 & & \\
$n=378+195+212+\mathrm{x}$ & & & \\
\hline
\end{tabular}

$n=$ number of new cases of diabetes;

${ }^{a}$ new cases with a hospital record and an insurance record,

b new cases with an insurance record but without a hospital record;

${ }^{c}$ new cases with a hospital record but without an insurance record;

$\mathrm{x}=$ unknown number of cases not registered in any source

ported were on insulin treatment. Therefore, the assumption was made that the large majority was indeed Type 1 . However, a strict classification by e.g. tissue typing, was not performed. The onset of diabetes was defined as the day of admission to hospital.

At the time of data collection for the study, most young persons with insulin-treated diabetes mellitus in Norway were entitled to a basic allowance from The National Insurance Institution as a compensation for their diet expenses. Some information on all persons receiving a basic allowance are registered by The National Insurance Institution. From the insurance register the following data were reported on persons with a basic allowance and the diagnosis diabetes mellitus: name, sex, date of birth, personal identification code and date of entry into the register. Date of entry is identical to the date of diagnosis in the medical certificate.

A person was thus registered as a new case of diabetes if she or he was treated in hospital with a diagnosis of diabetes mellitus for the first time within the study period and/or reported from the insurance register with a diagnosis of diabetes mellitus and an entry date within the study period, and if the person was below 30 years of age at the time of diagnosis.

If the date of diagnosis in the hospital report and in the insurance register were not identical, the earliest date was preferred.

In the present study, only persons with an age above 14.99 and below 30.0 years were included. The results for the younger age group 0-14 years were published previously [11].

\section{Validation of ascertainment}

The degree of ascertainment was established by comparing the data from the hospital departments and The National Insurance Institution.

The total number of new cases was 784, of which 211 were reported only from a hospital and not reported from the insurance registry. On the other hand, 195 cases which were reported from the insurance registry, could not be found in the hospital reports. Based on experience from previous studies that the data of the insurance register are reliable, the diagnosis and the time of diagnosis for these 195 cases were not ascertained by further contact with the hospitals.
Table 1 contains the basic data for estimation of completeness of ascertainment. The method employed was as described by Bishop, Fienberg and Holland [17] and the completeness for both sources was calculated in the following steps:

Completeness of source $A=C_{A}=(a+c) / N$

Completeness of source $B=C_{B}(a+b) / N$

$C_{A}=a /(a+b) C_{B}=a /(a+c)$

Probability of escaping both methods (sources) =

$\mathrm{X} / \mathrm{N}=\left(1-\mathrm{C}_{\mathrm{A}}\right)\left(1-\mathrm{C}_{\mathrm{B}}\right)$

Combined completeness of ascertainment source $A$ and $B=$

$\mathrm{C}_{\mathrm{AB}}(\%)(1-\mathrm{X} / \mathrm{N}) \times 100$

Completeness of ascertainment is presented as percentages with $95 \%$ confidence limits.

The combined completeness of ascertainment from both methods was $87.8 \%(85.8,89.9)$. This is a lower ascertainment probability than found in the age group $0-14$ years in the same period, $98.2 \%$ [11]. The lower probability is at least partly due to the lower number of persons receiving a basic allowance from The National Insurance Institution. The diabetic subjects have to personally apply for this financial compensation, and it is our experience that adult subjects are less prone to apply for an allowance than the parents of a diabetic child.

\section{Statistical analysis}

Age-adjusted incidence rates per year and per health region were analysed by the Mantel-Haenzel test [18]. The incidence tates across the years were tested with a test for linear trend in contingency tables [19]. The sex difference was tested by an ordinary chi-square test and the seasonal variation was evaluated with the method described by Roger [20].

\section{Results}

During the five-year period 1978-1982 our nationwide study revealed 784 new cases of Type 1 diabetes in the age group 15-29 years, 446 cases being males and 338 females. The mean yearly age-adjusted incidence was 17.0 per 100,000 for both sexes combined, 19.0 per 100,000 for males and 15.0 per 100,000 for females (Table 2). The male incidence exceeded the female incidence by $12 \%$ $(p<0.05)$. There was no statistically significant difference in incidence rate from year to year (Fig.1), and a test of linear trend in incidence across the years was not significant. Table 3 contains incidence data for the different health regions and the geographic variation is rather marked. The highest incidences were found in the southeastern part of the country (regions I, II), whereas the western (region III) and northern regions (regions IV, V) showed lower incidences. By dividing the country into a southern (I, II, III) and a northern (IV, V) part (Table 3), we found a significantly lower incidence in the northern $\operatorname{part}(p<0.001)$.

Table 2. Mean annual incidence rates of diabetes mellitus 15-29 years per age group and sex 1978-1982

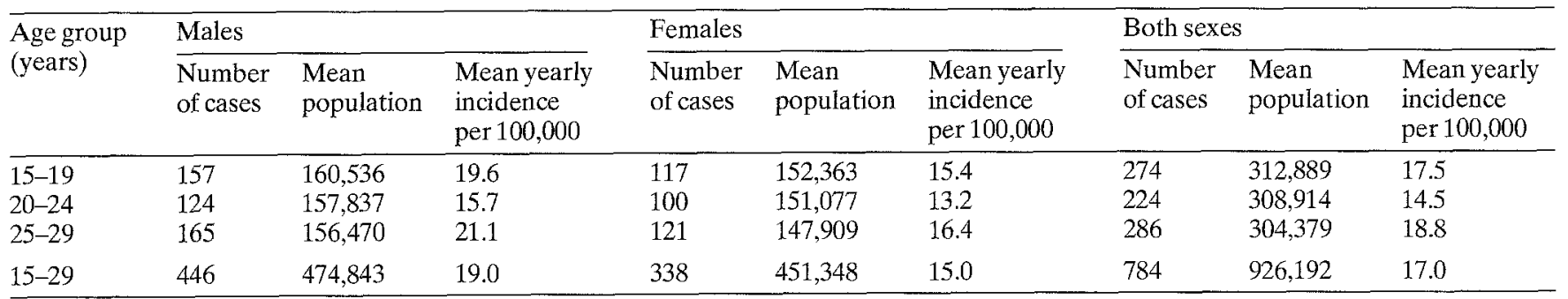




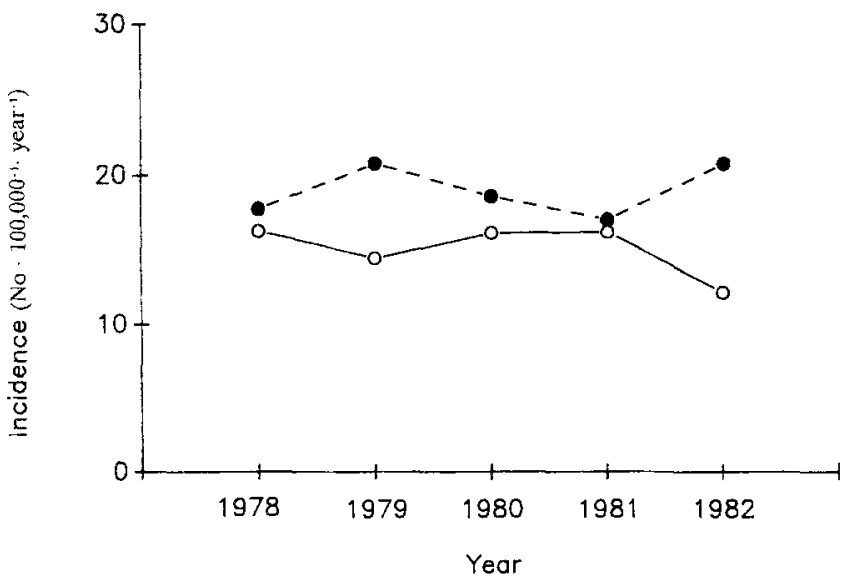

Fig. 1. Mean annual incidence rates of diabetes mellitus 15-29 years in Norway 1978-1982 per sex and year. (Males •---; females O-O)

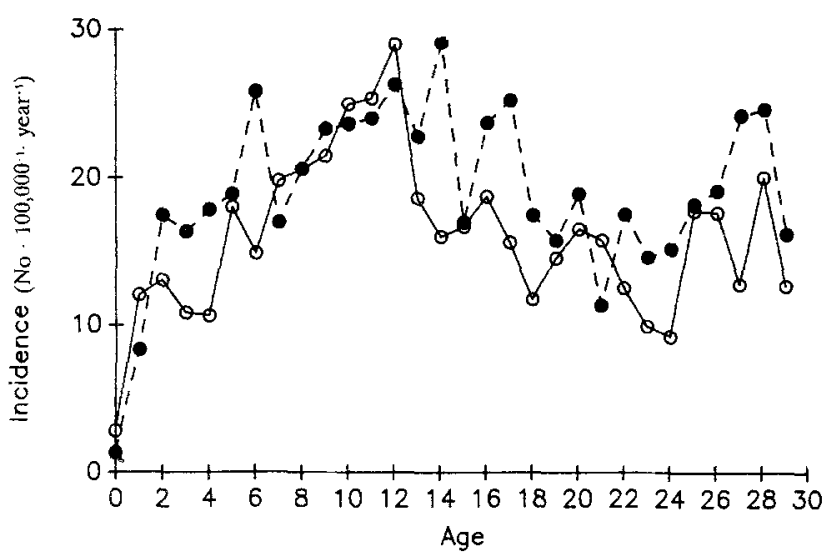

Fig. 2. Age-specific mean yearly incidence rates of diabetes mellitus 0-29 years in Norway 1978-1982 per sex. (Males -.--; females $0-0$ )

The age-specific incidence rates in the age group 15-29 years together with previously published data for the age group $0-14$ years in the same time period [11] are presented in Figure 2. From a maximum at 12 years of age the incidence decreased towards a minimum at 21 years for males and 25 years for females. Thereafter the incidence for both sexes again increased towards 30 years.

The highest number of new cases was registered in January and September, and the lowest number in July (Fig.3). The seasonal pattern was significantly different from a uniform distribution of new cases in both sexes $(p<0.025)$.

\section{Discussion}

The Nordic countries, including Norway, represent a highincidence area with regard to Type 1 diabetes $[1,2]$. In spite of small-sized populations these countries may therefore provide important epidemiological data, even during relatively short time periods. This potential contribution is particularly important since the Nordic countries are in general ethnically homogeneous, with reliable official health statistics.
In the present five-year study in the 15-29 year age group the mean yearly incidence of Type 1 diabetes was 17.0 per 100,000 . This is a considerably higher incidence than previously reported for the city of Oslo $[3,4]$. Admittedly, the earlier studies suffer from a lack of documented ascertainment. However, the apparent increase of incidence between the study of 1956-1965 [4] and the present investigation amounts to approximately $100 \%$. For this to be a spurious increase one has to presume that the earlier study had an ascertainment of only $40-50 \%$, which is not very likely. The incidence of diabetes mellitus in 15-29 year old subjects of south-eastern Norway has therefore most likely increased about two-fold during the 25-year period 1956-1982. A similar increase has previously been suggested for childhood diabetes [11].

Assuming that our material consists mainly of Type 1 diabetic subjects (see below), the incidence rates compare well with observations in Sweden during the year 1983 [9]. In that study the incidence of Type 1 diabetes was 18.5 per 100,000 for males, and 10.1 per 100,000 for females. The Norwegian and Swedish incidence rates are somewhat higher than reported from Denmark for the year 19701976 [7]. In all three countries there was a marked male excess of new cases, the male/female ratio being 1.5 in Denmark and Norway, and as high as 1.8 in Sweden. A male excess of Type 1 diabetes has previously been reported in children [11-13], but not as marked as in the $15-29$ years age group.

Studying 0-14 year old children, we have previously observed rather pronounced geographical variations of diabetes mellitus within Norway [11]. The particular geographic pattern, with high incidences in the south-eastern parts of the country and lower incidences in the western and northern regions, was also observed in the present work. As previously discussed, these geographic differences can hardly be attributed to the genetic background. One therefore has to consider environmental factors, as also suggested by the secular trend discussed above. At present one can only speculate whether these factors are of infectious, toxic or nutritional nature.

A seasonal variation of the onset of diabetes mellitus has repeatedly been observed in children $[7,12,21,22]$. It is of considerable interest that the seasonality of the incidence of diabetes, suggesting a climate-dependent triggering mechanism, is also present in age groups up to 30 years.

It is of interest to note the striking epidemiological similarities between our previous study of children [11]

Table 3. Incidence rates of diabetes mellitus 15-29 years per health region in Norway $1978-1982$ with $95 \%$ confidence limits

\begin{tabular}{llll}
\hline $\begin{array}{l}\text { Health } \\
\text { region }\end{array}$ & $\begin{array}{l}\text { New cases } \\
1978-1982\end{array}$ & $\begin{array}{l}\text { Mean popu- } \\
\text { lation 1978-1982 }\end{array}$ & $\begin{array}{l}\text { Mean yearly incidence } \\
\text { rate per 100,000 }\end{array}$ \\
\hline I & 320 & $1,534,921$ & $21.0(18.8,23.5)$ \\
II & 151 & 901,911 & $16.8(14.3,19.8)$ \\
III & 141 & 937,932 & $15.1(12.8,17.9)$ \\
IV & 91 & 696,181 & $13.2(10.7,16.3)$ \\
V & 81 & 560,643 & $14.6(11.7,18.2)$ \\
I + II + III & 612 & $3,374,134$ & $18.3(16.9,19.8)$ \\
IV + V & 172 & $1,256,824$ & $13.9(11.9,16.2)$ \\
\hline
\end{tabular}




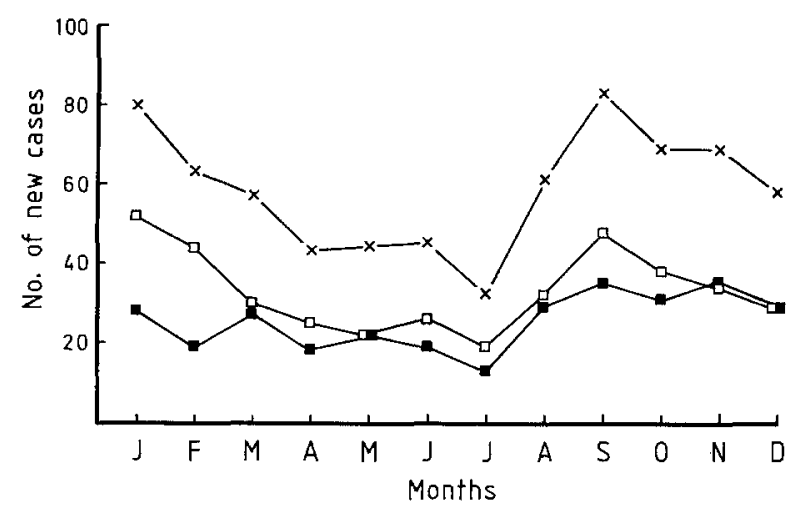

Fig. 3. Seasonal variation in the number of new cases of diabetes mellitus 15-29 years. (Males $\square-\square$; females $\square-$; both sexes $x-x$ )

and the present investigation. Both groups showed the same seasonal variation of onset, similar geographical pattern, and a similar sex ratio for the incidence of diabetes. Furthermore, when compared with earlier studies the two groups showed an almost identical secular trend. Since it is generally accepted that childhood diabetes is almost exclusively Type 1 the above-mentioned facts strongly support our assumption that Type 1 diabetes was the predominant type of diabetes in the material here presented. This assumption was further strengthened by a clinical evaluation performed at one of the largest clinics in the country (Haukeland Hospital) showing only $6 \%$ Type 2 diabetes in patients diagnosed in the 15-29 year age group (unpublished data). However, it is possible that Type 2 diabetes partly accounts for the apparently increasing incidence from the early twenties towards 30 years of age, as shown in our studies of the age-specific incidence.

Acknowledgements. This work was supported by a grant from The Norwegian Diabetes Association. We are grateful to colleagues who provided data for this investigation.

\section{References}

1. Diabetes Epidemiology Research International Group (1988) Geographical patterns of childhood insulin-dependent diabetes mellitus. Diabetes 37: 1113-1119

2. Rewers M, LaPorte R, King H, Tuomilehto J (DERI group) (1988) Trends in the prevalence and incidence of diabetes: insulin-dependent diabetes mellitus in childhood. World Health Stat Q 41: 179-189

3. Westlund K (1966) Incidence of diabetes mellitus in Oslo, Norway 1925 to 1954. Br J Prev Soc Med 20: 105-116

4. Ustvedt HJ, Olsen E (1977) Incidence of diabetes mellitus in Oslo, Norway 1956-65. Br J Prev Soc Med 31: 251-257

5. Palumbo PJ, Labarthe DR (1978) The incidence of diabetes mellitus in Rochester, Minnesota, 1945-1969. Adv Metab Dis 9: $13-$ 28
6. Allen C, Palta M, Alessio DJD (1986) Incidence and differences in urban-rural seasonal variation of Type 1 (insulin-dependent) diabetes in Wisconsin. Diabetologia 29: 629-633

7. Christau B, Kromann H, Christy M, Ortved Andersen O, Nerup J (1979) Incidence of insulin-dependent diabetes mellitus (0-29 years at onset) in Denmark. Acta Med Scand 624 [Suppl]: $54-60$

8. Barker DJP, Gardner MJ, Power C (1982) Incidence of diabetes mellitus amongst people aged $18-50$ years in nine British towns: a collaborative study. Diabetologia 22: 421-425

9. Östman J, Arnquist H, Blohme G, Lithner F, Littorin B, Nyström L, Sandström A, Schersten B, Wall S, Wibell L (1986) Epidemiology of diabetes mellitus in Sweden. Acta Med Scand 220: 437-445

10. Taha TH, Moussa MAA, Rashid AR, Fenech FF (1983) Diabetes in Kuwait - Incidence in the first 29 years of life. Diabetologia 25: 306-308

11. Joner G, Søvik O (1989) Increasing incidence of diabetes mellitus in Norwegian children 0-14 years of age 1973-1982. Diabetologia 32: 79-83

12. Reunanen A, Åkerblom HK, Käär ML (1982) Prevalence and ten-year (1970-1979) incidence of insulin-dependent diabetes mellitus in children and adolescents in Finland. Acta Paediatr Scand 71:893-899

13. Dahlquist G, Blom L, Holmgren G, Hägglöf B, Larsson Y, Sterky G, Wall S (1985) The epidemiology of diabetes in Swedish children 0-14 years - a six-year prospective study. Diabetologia 28: 802-808

14. Patterson CC, Thorogood M, Smith PG, Heasman MA, Clarke JA, Mann JI (1983) Epidemiology of Type 1 (insulin-dependent) diabetes in Scotland 1968-1976: evidence of an increasing incidence. Diabetologia 24:238-243

15. Burden AC, Hearnshaw JR, Swift PGF (1989) Childhood diabetes mellitus: an increasing incidence. Diabetic Med 6: 334-336

16. Soltesz G, Madacsy L, Bekefi D, Danko and the Hungarian Childhood Diabetes Group (1990) Rising incidence of Type 1 diabetes in Hungarian children (1978-1987) Diabetic Med 7: 111-114

17. Bishop YMM, Fienberg SE, Holland PW (1974) Discrete multivariate analysis: theory and practice. MIT Press, Massachusetts, pp 231-233

18. Rosner B (1986) Fundamentals of biostatistics, 2nd edn. Duxbury Press, Boston

19. Armitage P, Berry G (1987) Statistical methods in medical research. 2nd ed. Blackwell Scientific Publications, pp 371-374

20. Roger JH (1977) A significance test for cyclic trends in incidence data. Biometrika 64: 152-155

21. Siemiatycki J, Colle E, Aubert D, Campbell S, Belmonte MM (1986) The distribution of Type 1 (insulin-dependent) diabetes mellitus by age, sex secular trend, seasonality, time clusters and space-time clusters: evidence from Montreal, 1971-1983. Am J Epidemiol 124: $545-560$

22. Schober E, Frisch H(1988) Incidence of childhood diabetes mellitus in Austria 1979-1984. Acta Paediatr Scand 77: 299-302

Received: 18 June 1990

and in revised form: 11 December 1990

Dr. G.Joner

Pediatric Department

Aker University Hospital

$\mathrm{N}-0514$ Oslo 5

Norway 